\title{
Use of Alternate Fuels in Light Aircraft
}

\author{
Gary W. Johnson \\ Expert Technical Services
}

\begin{abstract}
Light aircraft are older, simpler technologies than modern cars, and thus easier to convert to utilize alternative liquid fuels. The specific differences between aircraft and automotive technologies impacts the choice of conversion approach. Fuels of technological interest include alcohols, ethers, and blends of these with gasolines or each other, but ethanol appears to be the preferred choice. Conversion must address metering, compatibility, timing, cold start, intake icing, and the delivery of increased fuel flow rates. Routine alternate fuels use implies that blends will be flown during the transition period from aviation gasoline to the new fuel. The two most important issues that must be addressed for safety of flight with gasoline-ethanol blends are moisture-induced phase separation and vapor lock behavior. Fuel density and handling characteristics appear not to be a problem. Research to date demonstrates that there are no real problems and many benefits when operating aircraft on ethanol fuel, and that there are no problems operating an ethanol-converted airplane on aviation gasoline. Research into the issues and operating characteristics of flying ethanol-gasoline blends is underway.
\end{abstract}

\section{INTRODUCTION}

Aviation gasoline is the last leaded product made in the world today. It requires a dedicated separate distribution system to serve a small niche market. It requires an exception from EPA for its continued use. Use of leaded fuel prevents the use of modern pollution-control and engine-control technologies, such as catalytic converters and exhaust oxygen sensors, on aircraft. All these things lend weight to the notion that leaded aviation gasoline will soon disappear.

The main reasons that aviation gasoline is still leaded are (1) conservative traditions that very strongly resist change, and (2) no unleaded hydrocarbon options have proven truly feasible for the replacement of the most widely available grade, 100LL. Two very attractive alternatives, driven mainly by a requirement for about
100 motor octane number (MON), are ethanol and ethyl tertiary butyl ether (ETBE). Methanol is also a candidate, but has less energy and more corrosive attack potential than ethanol, and is therefore less attractive in a practical sense.

Of these two, only ethanol has a quality-controlling specification (ASTM D-4806) already in place as is preferred by the Federal Aviation Administration (FAA). That specification was originally intended as a quality control on ethanol intended for blending use with automotive gasolines, but provides the same quality control over ethanol when used as a neat fuel, including general aviation. This "fuel grade ethanol" is a very dry material denatured with about 2 to $5 \%$ unleaded regular gasoline, or an alkylate precursor. This choice of denaturant makes the pool-burning flame visible enough for safety in accidents and fire-fighting operations.

Ethanol as a fuel has received many years' experimental use. Henry Ford made his model $\mathrm{T}$ so that it would burn either gasoline or ethanol, and of the two, it is said that he thought ethanol the better fuel. Ethanol has flown experimentally in light aircraft since the 1970's, and that includes both aerobatics, and a transatlantic crossing (see ref. 1).

Pending the eventual disappearance of leaded aviation gasoline, less expensive ethanol (about \$1.30/gallon vs about \$2) is probably the preferred replacement because of the wealth of experimental experience and the existence of a controlling specification. During the transition period from avgas to ethanol, blends will have to be flown as a practical matter. Thus, it is important to select the most appropriate conversion technologies for blends as well as neat fuels. Also, it is imperative, for safety-of-flight reasons, to address those problem areas that actually can and do occur with gasoline-alcohol blends.

This paper reports experiences of, and conclusions drawn by, the author while working with the research function of Baylor University's Department of Aviation Sciences: the Renewable Aviation Fuels Development Center (RAFDC). That department is headed by Dr. Max 
Shauck, who probably has more experience flying on alternate fuels than anyone in the world.

\section{AIRCRAFT TECHNOLOGY}

Light airplanes are much simpler, very much older technologies than modern cars, and are thus easier to convert to use alternative liquid fuels. Most are powered by gasoline-burning spark-ignition piston engines. The main differences with modern spark-ignition cars are (1) direct mixture control in mechanically-based metering devices, (2) operation at near-constant high power settings, (3) almost universal magneto ignition with fixed timing, (4) atmosphere-vented fuel tanks, and (5) an almost complete lack of software-based electronic engine controls. These differences substantially impact the nature of the preferred conversion to alternative fuels.

Direct mixture control means that the metering device need not be very sophisticated. The pilot is expected to adjust his mixture leaner for cruising flight, and to operate rich whenever high power is demanded, as in climb. Richer mixtures are also employed to prevent engine overheating at the more extreme conditions, by the mechanism of evaporative cooling.

Mixture control in aircraft with carburetors is accomplished very simply, either (1) by altering the pressure over the fuel bowl with a controllable vent leak to the throat vacuum, or (2) by using an oversized main jet variably-obstructed by a metering rod. The idle circuit and accelerator pump are rather similar to those used in automotive carburetors. In aircraft, there are usually no high speed or transitional circuits.

Pressure carburetors were invented to enable inverted flight by eliminating the float bowl free surface in favor of a regulated fuel pressure against a metering orifice within a closed chamber, with the pressure against the metering orifice mechanically varied by the throat pressure drop. They basically function as a very simple, all-mechanical, continuous-flow throttle body injection system. Adding a distribution device and continuous-flow injectors at the intake valves comprises one type mechanical fuel injection for aircraft, a direct analog to automotive mechanical continuous injection systems with port injection.

All these devices automatically provide only a rough approximation to proper mixture, at best. With direct mixture control, and a need only to operate at constant settings for extended periods, this rather primitive mode of mixture control is actually quite appropriate in aircraft. To adapt these types of metering devices for the needs of lower-air requirement alternate fuels (methanol, ethanol, ETBE, and blends), one need only extend the maximum flow capacities of the metering device circuits. The increase in total flow delivery capability from the fuel tanks demanded by lower air-requirement fuels must also be considered, for safety-of-flight. This usually means converting gravity-feed systems to pump-fed systems, which is not difficult to do, or to have approved by the FAA.

Unlike automobiles and trucks, aircraft are typically operated continuously at high power settings. Even when cruising relatively slowly, the shaft output is likely to be at least $65-75 \%$ of the maximum rated output of the engine. Climbing flight is generally conducted at power settings very near the rated power of the engine, and for periods of time far exceeding the usual requirements for passing and hill-climbing in ground vehicles. The crankshaft speed is also severely limited by propeller tip speed limits, so that these engines rarely operate above $2700 \mathrm{rpm}$. Consequently, these engines, generally air cooled, are significantly de-rated in their specific output, relative to modern automotive technologies, in order to provide durability and adequate life under these extreme conditions.

The most common types seen today in light aircraft are horizontally-opposed "case-and-jug" layouts of 4, 6, and sometimes 8 cylinders. Radial and in-line designs were once common, but are now rarely seen, except in antique aircraft.

Most production light aircraft have a dual-ignition magneto-based system of fixed timing, with an impulse coupling for starting retard. These features were originally a technology response to reliability requirements codified into aviation law during the 1920's, which still apply today. At the time, magneto systems were more reliable than breaker-point battery ignitions. Even so, redundancy was required to ensure acceptable safety of flight. These technology reliability considerations may no longer be strictly true with the advent of electronic ignition technology, but the aviation regulations requiring dual ignition still stand, and the new technologies now so familiar in the automotive fleet are not generally deployed in the light aircraft fleet.

The fixed magneto timing is set, usually about 25 to 28 degrees before top dead center (BTDC), so that maximum power may be applied without fear of detonation for extended duration in hot-day climbing flight at maximum weight, for which engine component temperatures are the hottest. At all other flight conditions, timing is thus seriously retarded, leading to lowered efficiency and higher fuel consumption.

Under these conditions, any beneficial effects on timing setting due to alternate fuels usage are rather minimal. In any event, changing the timing setting is inconvenient due to the equipment design, in which it was never intended that the timing setting would be easily altered. To date, the ignition timing is not changed in the RAFDC conversion approach. Changes in timing would depend upon knowledge of exactly what fuel, or blend, was in the tank. This is something not considered practical at this time by RAFDC.

Aircraft fuel tanks differ from those of modern ground vehicles in that they must be vented to the atmosphere. 
This is necessary because of the atmospheric pressure decrease at altitudes. Tanks light enough to fly, and also shaped to fit inside wings, may not further be pressure vessels. This has implications for both evaporative emissions, and for exposure of the fuel to weather (particularly moisture). It is already now a legal requirement, unfortunately not always properly observed, that a pilot must drain a small fuel sample from his tank's sump drain, inspect it for moisture and debris, and drain the tank of any water bottoms, before takeoff. Failure to do so has caused many general aviation accidents.

Software-based electronic engine controls for aircraft are only now beginning to appear. There is some recent history of experimental use, and few FAA-approved components or systems are yet available. No aircraft are as yet factory-equipped in this way.

\section{FUELS APPROPRIATE FOR SPARK-IGNITION AIRCRAFT}

Fuels of great technological interest include gasolines, alcohols, ethers, and blends of these materials. The basic fuel suitability requirements must address octane, stoichiometry, volatility, range of inflammability, density, viscosity, lubricity, and energy content. Miscibility and hygroscopicity properties with water can be crucial, especially with alcohols. The detailed way that the fuel burns can have great impact on thermal efficiency, emissions, and fuel consumption. Test results indicate that the alternative fuels (alcohols and ethers) are equal to, or superior to, gasolines in every way except (1) energy content, and (2) to some extent, cold start characteristics. Cold start can be compensated in a particularly easy fashion in aircraft. Low energy density has proven, in test, not to be particularly objectionable, due to an offsetting increase in thermal efficiency.

The prime spark ignition aviation fuel requirement is octane (a measure of detonation characteristics). Octane ratings for aircraft are defined differently from the automotive ratings, but all are tested in the same 1920'svintage "CFR" engine (see ASTM D-2699, D-2700, and D-909). There are four standard octane tests of interest here that are conducted in this CFR engine: Motor Octane (MON), Research Octane (RON), Aviation Lean (AL), and Aviation Rich Supercharge (ARS). The "pump octane" (PON), or "antiknock index" (AKI), reported for auto fuels is the arithmetic average of MON and RON.

$\mathrm{AL}$ is now no longer actually tested, but simply correlated from the more widely used and very similar MON results (ASTM D-2700). From about 75 or 80 octane to 100 octane, MON and AL differ by a fraction of a point. Above 100, the two scales differ by definition (octane number vs performance number scales), but correlate nearly linearly. Ethanol is reported by the National Renewable Energy Laboratory (NREL) to have a MON fractionally larger than 111 (ref 2). ETBE has a MON near 104, as reported by one of its manufacturers.
ARS has no correlation to MON or RON. It is the second number in the old military designation system for aviation gasolines, AL being the first, as in 100/130 (AL 100, ARS 130). Civil grade 100LL meets the same specifications, except that lead content is reduced from that in the older 100/130 military grade. The most detonation-resistant aviation gasoline ever made on a production basis is military grade 115/145, a product dyed purple which is no longer available, and which never had a civil equivalent. ARS top-of-defined-scale is 161 octane, corresponding to the detonation sensitivity of $6 \mathrm{cc}$ of tetraethyl lead in pure iso-octane. As far back as 1944, it was known from test data (ref. 3) that ethanol will not detonate in the ARS test, when $10 \mathrm{cc}$ per gallon tetra-ethyl lead in pure iso-octane will detonate. This is far above the top of the defined octane scale in that test. There are no available data in the ARS test for the ethers, but experimental flight use, including aerobatics, at RAFDC indicates similar high detonation resistance.

Unlike auto fuels (see ASTM D-439), aviation gasoline (see ASTM D-910) is refined to have lower volatility, and a flatter distillation curve. It still contains lead in order to achieve high octane rating (MON 100 for civil grade 100LL). In that respect, the most common aviation gasoline available today strongly resembles leaded auto racing fuel, and is sometimes used for that purpose.

\section{CONVERTING TO ALTERNATE FUELS}

Conversion as presently done at RAFDC for the use of alcohols or ethers, addresses the issues of metering, materials compatibility, timing, cold start, intake icing, and the delivery of increased fuel flow rates at adequate pressures in the fuel system. In addition to being engineering practicalities, these are all safety-of-flight issues, and must be addressed in the design and development, or modification, of any aircraft certified as airworthy by FAA. The additional issues of phase separation and vapor lock characteristics must be addressed for blends of alcohols with gasoline. Further issues of concern to FAA include (1) the effects of fuel density upon aircraft gross weight, and (2) any changes in the handling of the modified aircraft, especially the mixture control.

CONVERSION CRITERIA FOR METERING DEVICES The metering device, be it a carburetor, pressure carburetor, or continuous mechanical fuel injection, is rerigged to deliver up to twice as much flow at unchanged internal system pressures by the enlargement of suitable openings. This determines the maximum rich mixture delivery achievable with the mixture control (about 0.17 fuel/air vs about 0.09 on avgas). All the circuits and paths must be considered.

This flow capacity increase approach to conversion is reversible in the sense that plain gasoline still works fine; one simply now uses mixture control settings that are leaner than in the unmodified metering device. That level of maximum flow delivery allows full rich mixture ratios on a very cold day with 50-50 ethanol-methanol blends. 
This being the level selected for the available Supplemental Type Certificates (STC's) for certain O540 and $10-540$ Lycoming engines, by the manufacturer of the Bendix/Precision Airmotive RSA metering devices used on them, RAFDC continues to use that criterion.

In a carburetor, one merely drills out the jets for more area. Both the main jet and the idle setting must be so modified. Under the STC for the Lycoming O-235, the float position is reset, but this is really not necessary considering the availability of direct mixture control to the pilot.

In a pressure carburetor, or in a continuous flow mechanical fuel injector, the individual fuel injector orifices must be accurately drilled out, or larger units substituted, so as to pass more flow at otherwise the same fuel system pressure. In some metering devices, such as the Bendix/Precision Airmotive RSA-5, the lower idle valves must also be drilled out in order to pass sufficient flow. These modifications have the effect of increasing system flow capacity, and removing local bottlenecks to flow. For blends of a higher air requirement, including straight gasoline, one simply leans the mixture as appropriate.

The popular alternative approach, of adding a dedicated injector for extra fuel flow with alcohol, raises a question when trying to fly blends: how much added injection is actually needed? The answer depends upon the specific blend being flown. This requires that there be some (manual or automatic) way to detect and determine the blend composition. There is a sensor based on electrical conductivity available for use in certain flexible-fuel ground vehicle models that are currently offered, but no such sensors are available in a configuration suitable, or approved, for flight. Avoiding this issue would be better.

The added-capacity approach as done by RAFDC, with lean-down for blends and straight gasolines, is much simpler, and has much wider application, especially in aircraft not equipped with any electronic engine control capabilities at all. Such aircraft constitute virtually the entire existing light aircraft fleet. There is a setting for any blend somewhere within the capability of the mixture control. Knowledge of the blend composition is unnecessary.

MATERIALS COMPATIBILITY - Compatibility is generally not a problem with ethers or the less corrosive ethanol, and sometimes a serious problem with methanol. The worst exception is that all known clear structural plastics are very susceptible to vapor-phase attack by alcohols including ethanol, and possibly the ethers. Careful attention must be paid to eliminate the exposure of fuel quantity indicator covers and windshields to spilled fuels or accumulating fuel vapors. Substitution of glass may be required for some such items. This was done for the Piper "Pawnee" fuel quantity indicator as part of the STC that now allows the use of either avgas or ethanol as approved fuels in that craft (see ref. 4).
The other known compatibility issue is corrosion of aluminum surfaces, especially castings, in contact with ethanol. Behavior with ethers is unknown, but anecdotal evidence at RAFDC suggests that there is less of a problem with the nonpolar ethers than with the polar alcohols.

Corrosion of unprotected aluminum surfaces (such as tanks, hard tubing lines, and fuel pump or metering device castings) can be slowed by applying a conversion coating such as Alodine. This type of protection is available commercially, and is recognized as compliant with FAA regulations. Corresponding structures in ground vehicles have long been so protected.

The other unique item is vapor attack in narrow aluminum passages, such as those in a metering device. If the airplane is left sitting idle for months at a time (never a good idea), then the liquid fuel in these passages may evaporate. If the fuel were gasoline, then gum and varnish deposits may clog the passages. If the fuel were straight ethanol, then vapor-phase attack may produce an aerogel-like substance that can clog the passage. Up to a point, gasoline makes a fairly good solvent for this residue. Similarly, ethanol makes a fairly good solvent for gasoline gum and varnish deposits. The corresponding effects of gasoline-alcohol blends, and of ethers and ether blends, are unknown at this time, but under study at RAFDC.

COLD STARTING - Many solutions have been proposed. With auto fuels, having sufficient gasoline content in the ethanol or methanol seems to be quite effective. However, airplanes are a bit balkier in cold weather, due to the lower volatility of avgas. There is as yet no guarantee that any blends of avgas with alcohols or ethers will be rich enough in gasoline to start in cold weather, because the necessary formal cold-starting experiments have yet to be done. However, RAFDC will be doing those experiments soon.

The easiest, and surest, solution is the separate start fuel canister. This is appropriate in airplanes because it is customary to provide a hand-operated primer pump that squirts fuel from the main supply directly toward the intake valves in order to provide starting vapors. All production light aircraft currently in the fleet are so equipped.

In alternate-fueled light aircraft, the starting primer pump is simply re-routed to a separate small container of gasoline for cold start. Any gasoline will do, as starting is never accomplished at full throttle conditions. A one- or two-pint container is sufficient for about a month's worth of cold starts for the typical general aviation aircraft. This container must meet safety-of-flight requirements. Generally speaking, welded construction of stainless steel sheet is sufficient. A typical installation is shown in figure 1. 


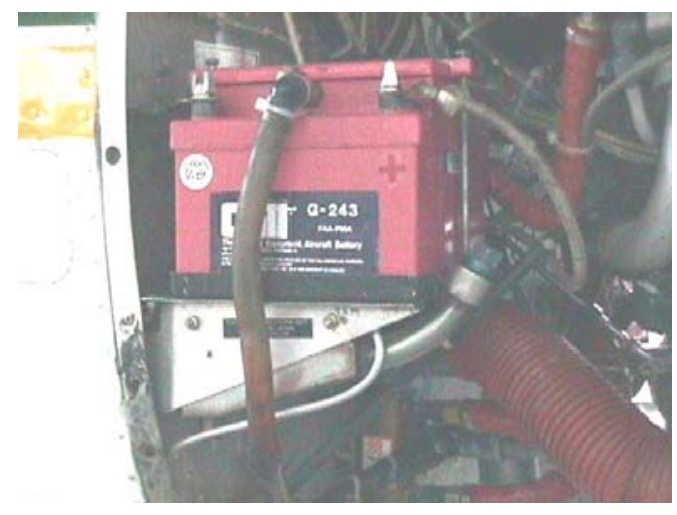

Figure 1 - Typical Start Canister Installation

The airplane engine ignites on the same volatile gasoline vapors as it always did, regardless of what is in the main fuel tank. Experience at RAFDC indicates that, once lit, even neat ethanol fuel burns fine during warmup. This also awaits demonstration in formal coldweather testing.

ICING CONCERNS - Experimental ground and flight test experience at RAFDC shows that ethers can provide equal or better power at essentially unaffected fuel flow rates as compared to gasolines. Similarly, ethanol shows better power at the cost of a very modest increase in fuel consumption. These trends are not in proportion to heating value, as there are substantial beneficial changes in thermal efficiency associated with these fuels (see figure 2). However, these relative flow rates do affect the potential for evaporative cooling and thus the risk of intake icing. However, in the case of port injection, that risk is apparently unrealized (see figure 3). With fuel injection located at the intake valves, icing is of little concern, regardless of the fuel latent heat capacity. Therefore one must consider which aircraft will remain carbureted, and which injected, to properly assess, and deal with, the risk.

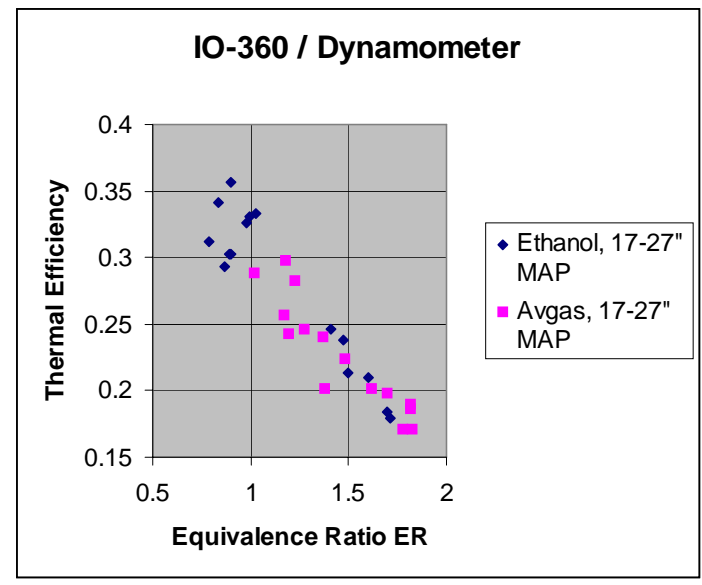

Figure 2 - Correlated Thermal Efficiency

Figure 3 - Port Injection Evaporative Potential is Large but Unrealized
Intake Charge Cooling

- Cruise Power a Full Power

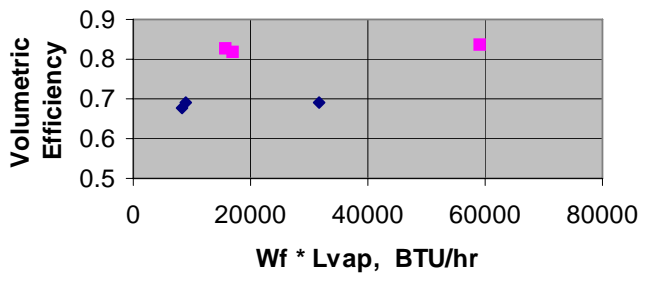

The latent heat capacity of ethanol is over twice that of aviation gasoline. This presents the possibility of enhanced intake icing, especially since a little more ethanol flow rate is required relative to gasoline, at equal power output levels, thus compounding the problem. Ethers actually have a lower latent heat of evaporation than gasoline, and require just about the same fuel flow rate as gasoline, thus presenting little added risk. Intake icing with alcohols is more of a risk in the larger engine sizes, which tend to be fuel injected thereby negating the risk, or can be so converted quite easily. In the smaller carbureted engines, it is best just to use the carburetor heat more often.

RAFDC's experience is with Lycoming engines, which have the air intake passages routed through the oil sump, where they draw heat for fuel vaporization and anti-icing effect. Continental engines do not route the air this way, and are reputedly more prone to intake icing. This design feature affects both icing characteristics and the completeness of fuel evaporation, which in turn can sometimes affect the combustion efficiency. These in turn affect many other things. The proper conversion technique for Continental engines, which must address this difference, remains to be investigated, but is quite probably very similar to that used for Lycoming engines.

RANGE OF INFLAMMABILITY - Mixture settings are a little more sensitive with ether, and less with ethanol, than with the base gasoline. This has little effect in actual flying, other than the need to finely-tune mixtures with the ethers a little more frequently. Ethanol will burn smoothly over an enormous range of mixture settings, so that the only consequence of mishandling the ethanol mixture setting is needlessly-shortened range. With ethanol, one needs to lean down cruising mixtures very aggressively, even more so than with gasoline. Tests indicate that lean-mixture hardware temperatures are generally lower on ethanol than gasoline (see figure 4), so that there are no overheat consequences for aggressive leaning on ethanol, as there sometimes are with gasoline. This happens even though the exhaust gas temperatures on ethanol actually tend to be a little higher than with gasoline.

Figure 4 - At Higher Power Settings, Cylinders Run Cooler on Ethanol vs Avgas

VISCOSITY AND LUBRICITY - Viscosity data for ethanol and ETBE are comparable to aviation gasoline (see ref. 5). This parameter applies to film lubrication 


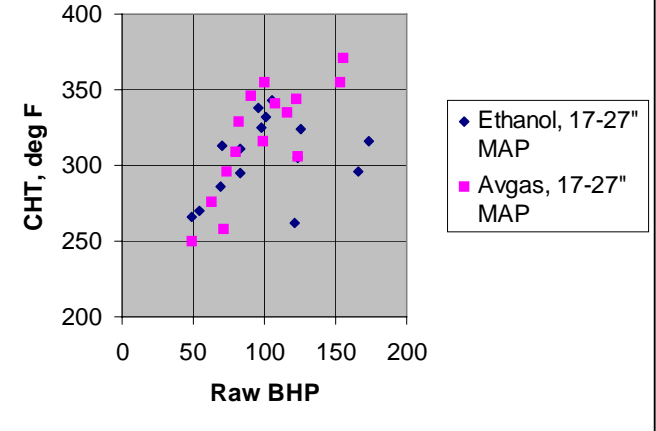

situations, as in steady running. Lubricity in standard friction tests for ethanol is comparable to gasoline (see again ref. 2). There are no corresponding data for ethers. These data apply to greasy-sliding friction (boundary lubrication) situations, such as during cold start. Anecdotal evidence suggests that ETBE presents no particular wear problem in fuel pumps, flow transducers, and metering devices. Certainly ethanol presents no particular wear problem in these devices. There are some reasons to believe that exclusive use of ethanol actually leads to longer engine wear life.

PHASE SEPARATION - FAA approvals for certain certificated engines and aircraft models to use ethanol or gasolines (but not blends) are already available. These include the Lycoming O-235, 0-540, and 10-540 parallel-valve engine series, and the Cessna 152 and Piper "Pawnee" aircraft. Operators of experimental aircraft may use alcohols, ethers, and blends as they see fit to take the risks. Routine alternate fuels use in aircraft implies that blends will have to be flown. However, there are two fundamental technical unknowns still to be resolved with ethanol, which is why there is as yet no approval of ethanol-gasoline blends for certificated aircraft. These issues are vapor lock and phase separation. Phase separation is not a problem with ether blends, but their vapor lock behavior is still unknown except anecdotally.

Phase separation in ethanol-gasoline blends occurs because water is insoluble in gasoline, but miscible in any proportion with ethanol, and because ethanol has a much higher affinity for water than for gasoline. Therefore, ethanol-gasoline blends that become contaminated with sufficient water separate into a lowerdensity dry gasoline layer floating on top of a wet ethanol layer. For all practical purposes, all the ethanol in the blend separates into the wet ethanol layer.

With ground vehicles, which typically operate at very low power settings, the sudden and irregular transition from burning the lower-energy wet ethanol layer to the higherenergy gasoline layer at over-rich settings, presents little problem, other than possibly stalling for over-rich operation. In aircraft at power settings nearly always exceeding $65 \%$ of the engine's rating, the transition causes power surges that can destroy the engine. In dynamometer testing at high power settings, this transition has caused severe engine damage. Phase separation is simply not to be allowed in flight applications of gasoline-alcohol blend fuels.
There will be two questions that every pilot must answer: (1) "is the blend fuel in my tank right now safe to fly?", and (2) "upon refueling, will the new blend separate?". The first question is appropriate because ethanol is hygroscopic, and will soak up atmospheric moisture over time in a vented tank. The second is appropriate because of the complex behavior of ethanol-gasoline blends in the presence of unpredictable amounts of moisture.

Up to now, with only water-immiscible avgas, the bottom sample customarily drawn from the aircraft tank sump drain shows the presence of any debris or water bottoms in the tank. For gasoline-ethanol blends of any significant ethanol content, water bottoms will no longer exist, right up to the phase separation point. This sample is still capable of indicating debris, however.

The physics of water-induced separation may provide both an indicator of separation upon refueling, and a means of determining precisely what blend is actually in the tank. Any blend will separate if enough water is added. This includes the denatured ethanol itself, for it contains a hydrocarbon denaturant. This must be taken into account in any measurements of blend composition.

The level of denaturant may change over time as the ethanol ages, due to differential evaporation (driven by differences in vapor pressure between gasoline and ethanol).

Further, some gasolines, although not currently avgas, contain some ethanol or methanol. This must also be taken into account for precise composition determinations.

By devising a water-separation test procedure and calibrating its accuracy, and by knowing or measuring the compositions of the base gasoline and denatured ethanol, it should be possible to make very precise determinations of blend composition. This can be done "in situ" in an aircraft fuel tank, with nothing more sophisticated than a couple of graduated glass cylinders and some clean drinking water. Development of that method is currently in progress at RAFDC. The purpose is for precise blend control during experimentation, which is something probably not needed for routine flying in a blend-burning fleet.

During that test procedure development, it was noticed that the dye in the gasoline goes with the gasoline during water-induced separations, so that the two layers had distinct colors (water-ethanol mixture is clear). It was further noticed that the separation boundary was easily visible regardless of any colors due to the differences in light reflection and refraction at the separation boundary.

Therefore, by comparing colors top to bottom, or by capturing a sample across the separation boundary so that it can be seen in the sample, one should be able to test an aircraft tank for separation before flight. RAFDC 
is currently working on the simplest and most practical form of such a test. Again, the final procedure must require no special equipment or special training, and must presume no prior knowledge of the composition in the tank.

Upon refueling, the new blend formed from tank residuals and whatever is being added, may separate even though neither component alone has a problem. This is because water tolerance in gasoline-ethanol blends is a function of blend composition as well as the amount of water added (see figure 5, published by the American Petroleum Institute for leaded premium autogas blends, ca. 1971). To avoid the trouble, the expense, and the serious risk to flight safety, of losing a tankful of fuel to separation upon refueling, there needs to be a check that is done before refueling.

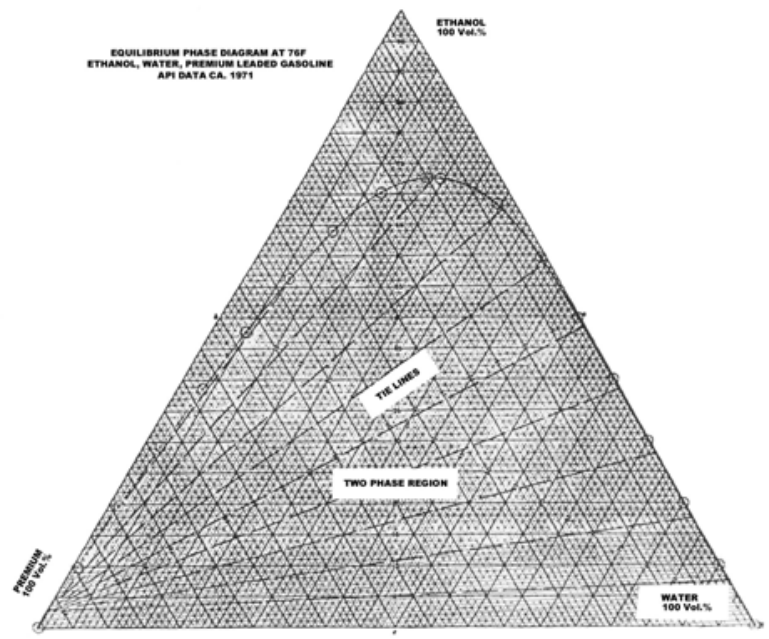

Figure 5 - API 3-way Phase Diagram, ca. 1971

A procedure used very successfully in experimental flight work at RAFDC is the "refuel blend sample". Under the presumption that the existing tank residuals are unseparated (because someone checked them!), a bottom sump drain sample then truly represents what is in the tank. With some knowledge of quantity-in-tank, and of how much is to be added, that bottom sample can be combined with the refueling composition in the same proportions as will exist in the refueled tank. If the sample separates, so would the tank. If not, then neither will the tank separate.

This refueling separation test procedure is receiving further attention at RAFDC to demonstrate its reliability, and to extend it to high altitude-capable aircraft. Such aircraft operate in cold air, where the fuel can cool in the tanks. Water tolerance in blends is also known to be temperature-dependent, being worse cold (see the Egloff curves of figure 6, ca. 1936).

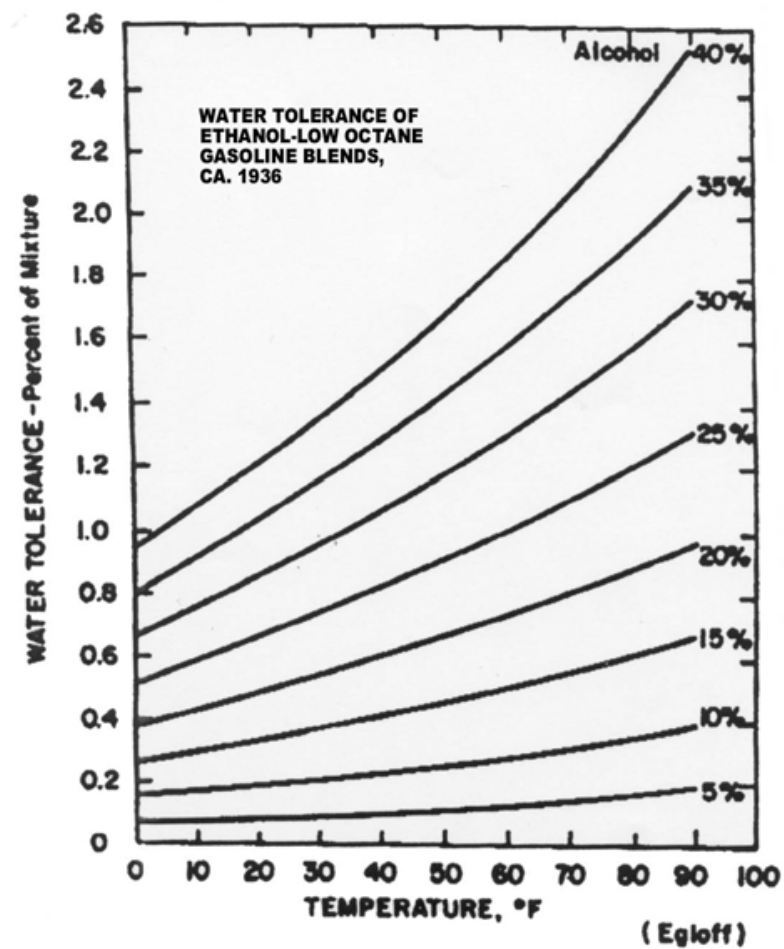

Figure 6 - Egloff Water Separation Curves, ca. 1936

VAPOR LOCK - Vapor lock occurs when essentiallystatic fuel in the one-way line dead-heading against the inlet valve of the metering device, heats up due to conditions under the cowling. If the hot fuel has a vapor pressure exceeding the pumped fuel line pressure, bubbles form. This restricts flow to the metering device, or cavitates the fuel pump, or both. Such an outcome causes engine failure, and possibly loss of the aircraft. It is a very serious problem in the air. The maximum $7 \mathrm{psi}$ criterion for avgas Reid vapor pressure in ASTM D-910 was an empirical way of preventing most vapor lock problems in flight.

With gasolines, another widely used (and FAArecognized) criterion is that fuel temperatures above the $10 \%$ distillation point are at risk of vapor lock due to vapor bubble formation. With pure substances such as ethanol and ETBE, the fuel must reach its normal boiling point at fuel system pressures, before bubble formation may even begin. Behavior of ethanol-gasoline blends falls in between, except that vapor pressure behavior is not linear with blend composition.

At about $10 \%$ ethanol, auto gas-ethanol blends sometimes (but not always) have a higher vapor pressure than the base gasoline, and thus can be (but are not always) more susceptible to vapor lock than straight auto gas. At about $22 \%$ ethanol, blend vapor pressure is always once again about the same as, or lower than, the base gasoline, and for blends richer in ethanol, vapor pressures then converge toward the lower ethanol value. 
Data with aviation gasolines are not yet available, but a somewhat similar, and substantially variable, trend is expected. The behavior definitely depends upon batchto-batch variations as well as volatility in the gasoline.

Solutions to this problem may be as simple as (1) fly no blends with vapor pressures higher than the base gasoline, or (2) install a to-from return line-type fuel system, so that the fuel never gets hot in the first place because it is always flowing. Since the advent of returnline systems in fuel injected cars, vapor lock has not been a problem. These problems and solutions are currently under study at RAFDC, with intent to propose workable procedures for an ethanol fleet transitioning on blends, including those presenting excess volatility risk.

\section{FLIGHT SAFETY: HANDLING CHARACTERISTICS}

The perceptive pilot may notice that the airplane is somewhat more powerful on alcohol than it is on gasoline. The amount of the change is more pronounced in engines of higher compression, but is typically about $10 \%$ or more. This increase is due to a large increase in thermal efficiency (see figure 7). How this effect varies across the range of blend fuels remains to be determined. That work is in progress at RAFDC.

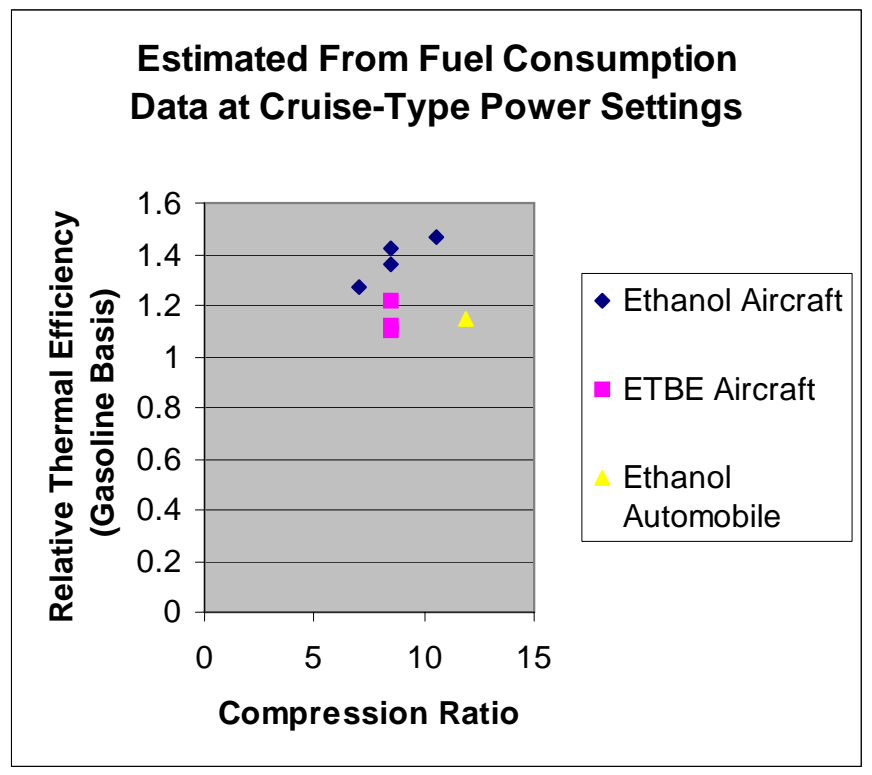

Figure 7 - Relative Efficiency vs Compression Ratio

The perceptive pilot may also notice that fuel burn rates are somewhat higher on all-ethanol fuel than on allavgas, at otherwise similar flight conditions. However, he will also notice that these consumption rates are only a few percent higher (10 to $20 \%$ ), not the $50 \%$ or more one might expect from a simple heating value ratio, unless he has seriously mishandled the mixture control. This is also due, at least in part, to the efficiency upgrade. How this varies across the range of blends remains to be seen. That work is in progress at RAFDC.
The perceptive pilot may also notice that ethanol can be leaned in cruising flight at reduced power settings much more aggressively than avgas. This has considerable impact on specific range. There are no adverse impacts to cylinderhead temperatures for such aggressive leaning with ethanol, so the most aggressive leaning possible is the recommended procedure. In reducedpower cruising, avgas can also be aggressively leaned without overheat risk, just not quite as lean as the alcohol. How this varies across the range of blends remains to be seen. That work is in progress at RAFDC.

There are still many myths about alcohol in engines. The facts are that exhaust gas temperatures (EGT's) will generally run the same or very slightly higher on alcohol as compared to gasoline, but that cylinderhead temperatures ( $\mathrm{CHT}^{\top}$ 's) will generally be the same or cooler, sometimes noticeably cooler, especially at the higher power settings. This cooler-hardware effect is definitely real, and many investigators have reported it (for example, see ref. 6). Trends across the range of blends remain to be seen, but no surprises are expected, based on preliminary results. That work is in progress at RAFDC.

Ethanol (and methanol and ETBE) have higher boiling points than gasoline. Vapor lock is very unlikely with these fuels, even less likely than with avgas, when used neat. The trend across the range of blend remains to be determined, although anecdotal experimental evidence would suggest no problems. Based on autogas-ethanol experience, we expect there might be some level of excess volatility at low-percentage ethanol blends, but this remains to be determined and the true risks assessed. Batch-to-batch variability in the gasoline is expected to play a major role in that behavior. That work is in progress as described above.

To safely fly blends subject to atmospheric moisture exposure, the pilot must execute a tank evaluation before every flight and every refueling that determines whether the tank is already separated. This is in addition to using the customary bottom sump sample to check for debris. Also, prior to refueling, the pilot must check the proposed blend for separation. The best information to date indicates that these tests, in their final form, will be very simple, and will require no special equipment or training.

The slightly-higher density of ethanol relative to avgas means that in a typical light aircraft, a full fuel load of neat ethanol weighs a few pounds more than a full fuel load of neat avgas. The difference is about $0.5 \mathrm{lb} /$ gallon or less (avgas density varies from batch to batch). When operating at max gross weight on hot days, perhaps the simplest compensation for this density is to reduce the fuel fill by a few gallons, or to reduce payload a few pounds, to stay within gross weight limits.

Effectively, one simply reduces the max gross weight allowable by the worst-case difference in loadable fuel weights, to offset the increase in fuel weight when fueled 
with neat alcohol. For example, with 40 gallon capacity, one lowers the allowable gross weight by only 20 pounds to offset any possible increase. The added power available on alcohol would also tend to offset the effects of extra fuel weight, thus affording a second measure of improved flight safety.

\section{CURRENT STATUS OF TESTING}

In 1998, under contract to FAA, RAFDC conducted extensive ground and flight tests of the neat fuels ethanol, ETBE, and 100LL avgas. The fuels were tested in an IO-360 engine mounted in a dynamometer stand, and an $10-540$ engine powering a PA-25 "Pawnee" agricultural plane. The results of that work, and other complementary work, verified that there are no problems running properly modified aircraft on neat ethanol or neat ETBE, vs neat avgas. This work also verified that there are no problems and no performance changes running neat avgas in the ethanol-modified aircraft. Choice of neat fuel is thus completely "transparent" to the pilot (see ref. 7).

In 2001, RAFDC is once again under contract to FAA, to investigate ethanol-avgas blends. That work is now in progress, with some pre-contract experimental data already available to help support that effort. Areas of concern include (1) vapor lock, (2) phase separation, (3) gross weight / density, (4) defining the changes, if any, for handling mixture across the range of blends, and (5) determining if there any impacts to any other flying qualities, handling characteristics, or operating procedures. This author is proud to be once again associated with RAFDC in that effort.

\section{CONCLUSION}

Obviously, more work remains to be done, as outlined above. Specifically, this is the flight testing of avgasethanol blends, as currently sponsored by the FAA. Based on the results obtained so far, RAFDC expects no surprises, and anticipates no serious problems. It appears that light aircraft modified by the added-capacity approach will handle exactly the same on blends as they do on neat avgas or ethanol. Piloting procedures will apparently be unchanged, with three minor exceptions.

First, when operating the modified aircraft on avgas or blends that are nearly all avgas, the full-rich position of the mixture control is no longer on the forward travel stop. Putting it there on such a fuel will likely cause engine stoppage due to over-rich operation, but no damage. It will restart in-flight as soon as the mixture is leaned enough to burn. This is primarily a pilot training item, although convenient paint marks on some styles of mixture controls have proven very useful as a reminder and a guide (see figure 8).

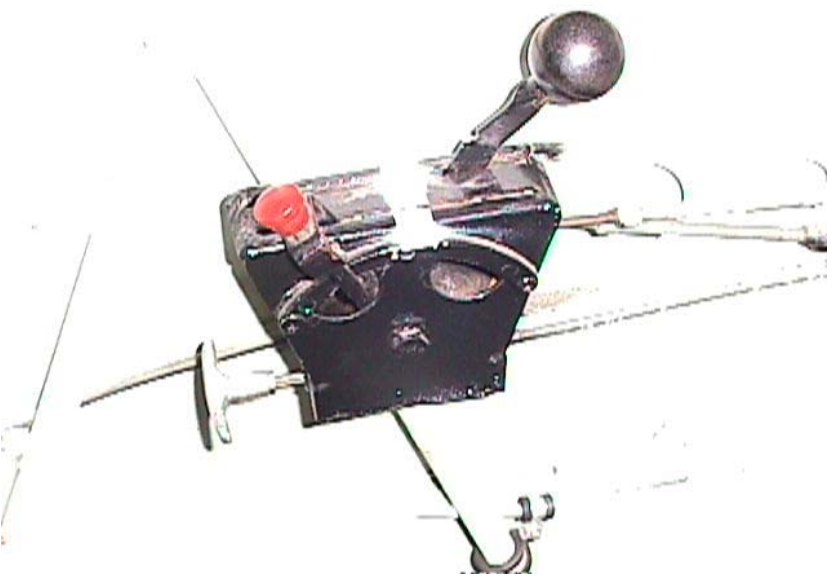

Figure 8 - Avgas Mark on "Pawnee" Mixture Control

Second, the fuel sample procedures to prevent phase separation may not be neglected. Legally, a fuel sample check for water bottoms and debris is already required for avgas-only aircraft. However, the flying public absolutely must have the discipline to perform these checks without fail prior to flight, in order to fly blend fuels without risk of phase separation. Once avgas is no longer available at all, and only ethanol may be had, moisture content is no longer a problem. This is definitely a pilot training / pilot education problem, not a technical problem.

Third, specific range is slightly reduced when operating on alcohol, and presumably on alcohol-rich blends. This presents very little problem in most operations, as range in light aircraft is usually more limited by the pilot's bladder capacity than by his airplane's fuel tank capacity. For long over-water flights, this effect must be taken into account conservatively when estimating range. This is more a pilot education issue than a technical problem. It only requires awareness of what the fuel quantity indicators, the map, and the clock are telling you in flight, something already legally required.

In all other respects, all the data obtained to date by RAFDC indicate that operating light aircraft modified by the added capacity approach on alcohols, gasolines, or alcohol-gasoline blends is completely "transparent" to the pilot. There is no change in what he would do as compared to operating only on avgas. There is no damage potential to the engine or airplane.

In short, there are no technical or practical reasons why we should not to do this.

There is enormous potential for applying electronic controls and pollution improvements in future production aircraft if the lead disappears. There are energyindependence benefits associated with a home-grown renewable fuel. There are pollution-control benefits associated with switching over to ethanol, even in older aircraft lacking pollution controls. The operating costs, both direct (fuel cost) and indirect (extended overhaul intervals), go down on ethanol. 
There are plenty of technical and practical reasons why we should do this.

Therefore, we ought to finish addressing the remaining issues as expeditiously as is possible, and just do it.

\section{ACKNOWLEDGMENTS}

The author gratefully acknowledges his debt to Dr. Shauck, and his department and staff, for the use of the data and the opportunity of working there.

\section{REFERENCES}

1. Shauck, M. \& Zanin, G. (1991). The First Transatlantic Crossing in an Aircraft Powered by Ethanol Fuel. Paper presented at the Eighth International Symposium on Alcohol Fuels, Florence, Italy.

2. Bailey, K. \& Russell, J. (1981). Emergency Transportation Fuels: Properties and Performance. Warrendale, PA: Society of Automotive Engineers. (SAE paper 810444)
3. Schunke, E. (1944). [data for neat ethanol in the ANF-18 rich supercharge test]. Unpublished raw data.

4. Ethanol "Pawnee" STC, FAA project number ST 4782 SC-A, approved 2000.

5. Bechtold, R. (1997). Alternative Fuels Guidebook. Warrendale, PA: Society of Automotive Engineers.

6. Cooper, G. (1995). Experiences with MethanolPowered Aircraft. Paper presented at the First International Conference on Alternative Aviation Fuels, Waco, Texas.

7. Johnson, G., Shauck, M., \& Zanin, G. (1998). Performance and Emissions Comparisons Between Avgas, Ethanol, and ETBE in an Aircraft Engine. Paper presented at the twelfth International Symposium on Alcohol Fuels, Beijing, China.

\section{CONTACT}

The author is currently an independent engineering consultant, doing business under the name Expert Technical Services. He can be reached by phone at 254-840-9629, by mail at 5886 New Windsor Parkway, McGregor, Texas, 76657, and by e-mail at Gwi5886@aol.com. 